\title{
Getting an Education in Edmonton, Alberta: The Case of Queer Youth
}

\author{
ANDRÉ P. GRACE \\ KRISTOPHER WELLS
}

André P. Grace (andre.grace@ualberta.ca) is an academic whose work focuses on sex-and-gender issues and inclusive education. He received the 2001 Sheryl McInnes Award in recognition of his service to the gay and lesbian community of Edmonton. Kristopher Wells ( $k$ wells@ualberta.ca) is a master's student in educational policy studies, University of Alberta, and a facilitator with Youth Understanding Youth, Edmonton's queer youth outreach group.

\section{Introduction: School's Out?}

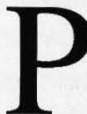
rotection against discrimination on the ground of sexual orientation is included in both the Canadian Charter of Rights and Freedoms and human rights legislation in all provinces and territories except the Northwest Territories (EGALE 1). Despite this, "schools remain one of the last bastions of tolerated hatred toward glbt [gay, lesbian, bisexual, and transgender] people" (STA 2). Sexand-gender youth minorities still struggle to be seen and heard and to remain safe in Canadian schools. Their struggles for a voice and recognition, which contest the limits placed on their school experiences, define the contemporary queer phenomenon in Canadian public education. However, while queer students are finding the courage to come out in greater numbers than ever before, most still run the gauntlet of a repressive contingent of socially conservative school-district personnel, homophobic administrators and teachers, rightist clergy, and unreceptive parents. They experience a barrage of mental, emotional, and physical violence as they confront a "Grades not AIDS" conservative mindset (Ritter 3). Queer students have to be brave as they face social stigmatization, public animosity, and their fears of being alone without the support of family, friends, school, 


\section{8 / Grace \& Wells}

and community (NEA et al. 3). Outreach groups - such as GayStraight Alliance clubs in some schools nationally and Youth Understanding Youth in Edmonton - become spaces of hope and possibility for these queer students. Here we explore aspects of these initiatives regarding outreach to queer youth in Alberta.

\section{Getting a Formal Education: Queer Youth and Schooling in Alberta}

In $A$ Vision and Agenda for Public Education, Alberta's Education Partners, including the Alberta Teachers' Association, have set directions for a system of public education organized around a commitment to educate all children well. The partners declared, "It is essential that public education foster and support the intellectual, social, physical, emotional and spiritual development of each child" (1). Necessary conditions stated to help achieve this mission include (a) the creation of safe-and-caring school environments where students sense that a milieu of trust, respect, and inclusiveness prevails; (b) the provision of programs and support to provide equitable opportunities so children at risk may stay and succeed in school; and (c) the recognition of the student-teacher relationship as the central dynamic that can enable all students to be, become, and belong as they grow and develop as persons in school. However, while these directions have been taken up more overtly across such issues of difference as race, gender, and class, the establishment of conditions necessary to educate queer children well requires a substantial and focused effort. Kathryn ${ }^{1}$ - a lesbian high-school student who was living in a safe house at the time she was interviewed - describes her school experience in Edmonton in a way that stands as an exemplary testimony to the need for work that addresses sexand-gender differences in educating youth:

The high school I went to in grades 10 and 11 was awful. It was very, very homophobic. It's funny. When I got involved

\footnotetext{
'Kathryn and other queer youth whose reflections and writing appear in this piece are members of Youth Understanding Youth, which is an Edmonton-based support group for lesbian, gay, bisexual, transgender, straight, and questioning youth who are under the age of 25 . They were participants involved in a research project that we designed to identify needs and to build supports for queer youth in their school and community settings.
} 
in going to gay bars, I even saw some of my teachers that are gay. But why aren't they out in school? I don't know, but I wish they were. Then at least I could have gone to them. But I can understand why they're not because it is a really homophobic high school. If I ever did hear a queer-related topic, it was always something negative. So I always had to shut up because I was too scared ... I remember when we were going over the Canadian Charter of Rights and Freedoms in class. When our teacher was going through it, and reading it and telling us our rights, $I$ just wish that he talked about gay rights as much as he talked about the other rights. I just feel that if teachers are open to this issue then kids also will be ... After I had my depression in Grade 11, I ended up being in the hospital for half of the school year. So that was it for that school. Other kids who are also queer go to that school, and they also weren't out. Sometimes I see them in the community, and they are just so out and everything. But when they are in the school, they are just like the straightest kids.

Kathryn's story of omission and invisibility highlights the fact that schools do not "truly care about ALL of our students" (STA 2). Like all students, queer youth confront their differences in schools. However, they find themselves uniquely and simultaneously included and excluded: included as youth, but excluded as queer youth (Epstein/ Johnson 133). They learn to manage their stigmatized queer identities with little or no support from mainstream educational and cultural institutions. However, if schools are to be safe, inclusive learning environments, then they ought to take up issues of sexual orientation so (a) straight students learn about queer differences and (b) queer students see themselves represented in curriculum and instruction. Unfortunately, educators often avoid discussions about queer persons and families built around a queer partnership. Key reasons for avoidance are often grounded in personal fear:

Why are we [educators] so fearful? There are some common elements to our fears that include: 1. Lack of knowledge about glbt people and same-gender families. 2 . Worries that discussing glbt relationships means talking about "gay sex" at school. 3. Fear of parent reactions. 4. Worries about administrative concern and lack of support. 5. Religious 
and/or moral objections of parents and the community at large. (STA 3)

Queer youth, who live with this fear and its fallout as much as educators do, see it for what it is. For example, Tim, a gay first-year university student, situates the fear this way: "People don't know you so they fear what you are and what they might become."

The avoidance of queer issues contributes to queer students' negative experiences of schooling, which are often marked and marred by isolation, self-hatred, self-abuse, fear of humiliation, and lack of social (peer, school, family, and community) support (NEA et al. 3). Queer students are more likely than straight peers to (a) miss school because they are afraid, (b) be verbally or physically threatened by other students, and (c) have their belongings vandalized (NEA et al. 3). Constantly subjected to a learning culture of threat, risk, and danger, queer youth exhibit higher rates of (a) emotional distress, (b) depression, (c) suicide attempts, (d) sexual promiscuity, and (e) alcohol and substance abuse (Friend; NEA et al.; Ryan/Futterman). They often have nowhere to turn because there is an absence of queer role models in schools. Marie, an eighteen-year-old lesbian highschool student, stresses the importance of visible queer role models: "They help us to imagine our future lives and to say 'Yes, I can do that.' When I see people live openly gay and successful lives, it shows me that I can have a job and a relationship too." However, queer teachers frequently choose invisibility as their way to mediate antiqueer cultural bias and social stigmatization in their life and work. Sadly, when teachers hide their queerness, queer and questioning youth also pay the price for this invisibility.

Nevertheless, more queer students are fighting back when it comes to their education. Indeed, “the [queer] 'problem' that teachers and administrators have for years been too frightened to confront is suddenly walking through the schoolhouse door every weekday morning" (Bull 29). Some queer students have been working to set up gay-straight alliance clubs in at least a few Canadian schools as part of antisexist, antihomophobic efforts to counter discrimination and exclusion that limit their experiences of schooling. This work takes its toll as these students are pushed into greater awareness of real life in schools, which mirrors life in the larger culture where antiqueer fears, phobias, bigotry, and prejudice are pervasive.

It is important that groups with responsibility to educate all 
children well take the initiative to provide social and cultural supports for queer students. In recent years, the Alberta Teachers' Association (ATA) has included protection against discrimination on the grounds of sexual orientation for teachers and students in its Declaration of Rights and Responsibilities for Teachers and its Code of Professional Conduct (see Teaching in Alberta). However, while the neighboring British Columbia Teachers' Federation has moved to endorse publicly the establishment of gay-straight alliance clubs in provincial schools, the ATA has yet to do so. Thus establishing these clubs remains an uphill battle in Alberta. Yet it is an important one, and part of larger queer advocacy initiatives needed to support the right of queer students to learn in safe, healthy, just, welcoming, and caring school environments.

\section{Getting an Informal Education: Youth Understanding Youth as a Safe and Caring Learning Space for Sex-and-Gender Minority Youth in Edmonton}

Queer youth fear or face prejudice, discrimination, violent behavior, and language assaults in three key social spaces: the family, the school, and the community (NEA et al. 3). Moreover, in response to the social stigma surrounding homosexuality, queer youth commonly withdraw from typical adolescent peer group experiences that are usually interactions in heterosexualizing, alienating contexts (see Ryan/Futterman). Finding little or no space in mainstream social spaces, queer youth seek alternative social spaces. Edmonton's queer youth speak about the city's gay bars and Internet adult chat rooms (such as Gay.com and Internet Relay Chat's [IRC] \#gayedmonton) as risky spaces where they attempt to socialize. Such socialization can contribute to increased pressure to engage in high-risk, "anonymous sexual behaviors that have a direct correlation with increased STD, AIDS and drug and alcohol abuse" (Ryan/Futterman 107). However, for some queer youth, the risks are outweighed by the desire and need for any available means of education that can help them understand their sexual feelings, isolation, and alienation (Ryan/Futterman 73).

In this milieu, an informal learning space like Edmonton's Youth Understanding Youth (YUY) provides a welcome and needed space for questioning, searching queer youth. By providing "supportive, age-appropriate activities" for queer youth, it also provides 
"opportunities for normal socialization and interaction with peers" (Ryan/Futterman 73). In its statement of philosophy, YUY describes itself as "a self-supporting volunteer group that strives to create a safe environment in which youth can explore and express their interests and needs in an atmosphere where they can expect to be supported and respected for their contributions and unique individual differences" (YUY 1). YUY is a peer support and discussion group that welcomes all young people who want to investigate sex-andgender differences in a physically and emotionally safe space where confidentiality and privacy are respected. The group operates using guidelines that respect the equality, uniqueness, identity, and integrity of each group member. It provides this statement of purpose:

The mission of Youth Understanding Youth is to provide a warm and friendly place where lesbian, gay, bisexual, transgendered, straight and questioning youth, who are under the age of 25 , can gather together to have fun and learn about themselves and others in a safe, supportive and caring environment. (YUY 1)

YUY starts its meetings by having a youth cofacilitator read the philosophy statement. Then, cofacilitators and group members sit in a circle and introduce themselves. Next, everyone is invited to answer a youth-created icebreaker question. For example, members might respond to one of the following starter questions: What do you find most attractive about another guy or girl? Who is your favorite queer singer? What is your favorite queer-themed movie? Following the icebreaker exercise, everyone is invited to share his or her positive and negative experiences for the week. For example, at a recent YUY meeting, one gay-male youth announced, "I have a new boyfriend and things are going really well." A lesbian youth shared, "I got kicked out of my house last week." Another gay-male youth added, "My parents are still not accepting me, but the positive thing is that we are still talking."

These opening activities usually take forty-five minutes. After a fifteen-minute break, group members participate in the evening's planned event. The group meets every Saturday at the Gay and Lesbian Community Centre of Edmonton (Suite 103, 10612 - 124th Street) from 7-9 pm. YUY can be contacted by email at <yuyedm@hotmail.com>. They also have a Website: <http:// www.yuyouth.tripod.com>. Testimonials at this site reiterate the 
importance that queer youth place on Youth Understanding Youth as a support in their lives. For example, Mark wrote these comments:

I went to my first meeting this Saturday, and it was an awesome experience that I'm sure I'll relive again next Saturday. ... Awesome Website! I don't know what I'd do without you guys, and I'm sure a lot of people agree with me. In life you go through tough times and good times. Then you go to the meeting and talk about it. That's life, and it's great! See-ya all next Saturday. Peace guys.

YUY holds a planning night once every two months so youth group members can plan activities and topics that adult and youth cofacilitators will help deliver in weekly meetings during the twomonth interval. The meetings have traditionally been loosely designed around five alternating themes. Theme 1 is Discussion Night where guest speakers engage topics such as spirituality and safer sex, or group members discuss topics including relationships, coming out, dating, and school issues. Theme 2 is Sharing Our Stories where one or two group members take the opportunity to speak about coming out and/or other aspects of their lives in dialogue with other group members. Theme 3 is Activity Night where group members take part, for example, in drama games, bowling, and Pride Day planning. Theme 4 is Fringe Night where group members share special talents (such as dance, poetry, music, and art) or something that has special meaning to them (such as pictures, quotes, or collectibles). Theme 5 is Movie Night where group members watch gay-themed, contemporary movies like Jeffrey (Ashley 1995), The Broken Hearts Club (Berlanti 2000), Priest (Bird 1995), or The Hanging Garden (Fitzgerald 1998).

YUY provides a fugitive learning space where queer youth actively participate to create a sharing space in which they can make sense of themselves and those around them. For queer youth, this self-determined, informal education becomes a political and personal practice that "intersects with a wide range of overlapping and shifting sites of learning" that contest dominant cultural modes of expression, containment, and regulation (Giroux 15). YUY becomes a safe and caring space to build and integrate positive sex-and-gender identities. The work to help queer youth grow and develop as self-confident persons who accept and love themselves takes time. It requires access to supportive peers and adults, access to accurate information, and a 
connection to a community in which accommodation and validation are provided (Ryan/Futterman 20-22). It is important work since queer youth who have "developed and integrated a positive identity show better psychological adjustment, greater satisfaction, and higher self-concept, with lower rates of depression or stress" (Ryan/ Futterman 20). Justin, a twenty-year-old youth group member who works in Edmonton, considers Youth Understanding Youth to be an important source of support in his life. He affirms, "It's just a place to go and be yourself. You don't have to be so closed up. It just makes you feel good inside." Kathryn, a regular at YUY meetings, also speaks to the important role that the group plays in building her self-confidence and self-esteem:

Youth Understanding Youth is a little group, but it's still really big to me. It's something to do on the weekend ... I need that insurance that there [is] a group of queers getting together and doing some good, fun, positive activity. For me, the group is inspiring. The kids are really just fantastic. They are very intelligent kids. They all have jobs. Most of them are looking for a career, and they have really inspired me to actually go on with my life and not give up. When I hear of each one of them graduating, I'm like oh, I want to do that too. She's gay and I'm gay. She has also been kicked out of home, but she made it. I can do it too. That's why I come here to hear more success stories and to get hope.... I feel like I have no family, but this is sort of family for me. This is the closest thing to me right now. I have no one else that I can talk to about relationships, about life, my goals, my hopes, about my dreams. All the people that I know are from this community, and I'm comfortable and I'm myself. I'm not afraid of saying anything. I'm myself. I dress the way I want. I talk the way I want. I'm comfortable. That's all that matters.

\section{Concluding Perspective}

Community youth groups like Youth Understanding Youth provide an important social space for queer youth to explore being, becoming, and belonging. However, relationships with peers are not enough. Queer youth also identify teachers as a most important source of support to help them deal with their problems and concerns (Ryan/ 
Futterman 74). Educational interest groups need to work together to enable teachers, especially queer teachers, to interact with queer youth as mentors and supporters. Gay/straight alliance clubs can be one important site of mentoring and support. The Alberta Teachers' Association needs to continue its work to address issues in relation to sexual orientation and schooling, and it ought to support ventures such as the establishment of gay/straight alliance clubs in Alberta's schools.

Now follow some expressive arts testimonies by members of YUY.

\section{Lyrics \\ LiNCOLN Ho}

Lincoln is an eighteen-year-old gay university student. If you would like to learn more about Lincoln and his creative writing, visit his website at $\langle w w w$.lincolnho.8m.com>. Of this piece he writes: "I wrote this story on September 14, 1999, from my friend's perspective. He is going through a picture album and he flips to a page with a picture of me on it. The title of my story is 'Lyrics' because many closeted youth find few ways to communicate with the world and lyrics have traditionally been useful tools for youth who have nowhere to turn. I'm not good at expressing my emotions physically, so I use words to do that for me."

This page of pictures is of my friend Lincoln. For as long as I have known him, he has always amazed me. There is so much about his character that I admire, and I respect him a lot for handling his difficult times the way he has. I know that he's been through a lot, mostly because he's gay. He's still standing proud though, which is a great quality that I very much like about him. I don't really care that he is gay. He sure has changed a lot of the stereotypes of gay people that I used to think were true.

He and I met about a year ago in grade ten through our interests in music. He and I both really enjoy listening, composing, and learning about music. We both love to write songs and sing. In fact, he once lent me a tape of his songs sung a cappella. They all seemed to be about suicide, and how the world sucks and everything. I guess 
he likes that type of music for some sort of reason. I really don't know why he always writes all those depressing songs.

Anyway, deep inside the Lincoln who everybody knows, there is a stronger Lincoln who is locked up just because of his surroundings. He can achieve so much because he can forget and forgive so many things that happen to him. I didn't really know that he was gay until he told me. It just shows how he can be such a good actor. However, he doesn't like acting, and he says that it's not his thing to show emotions.

In the beginning, he didn't talk about himself very much, but the inner struggles that he has been going through have given him some rough times. When he started to talk to me about himself, and what had happened in his life before, it amazed me even more that he hasn't committed suicide. I'm very serious! According to what he said about himself before I knew him, he was on a roller coaster with very extreme highs and lows all because of something called discrimination. And by the way, studies show that gay and aboriginal youth have some of the highest suicide rates in Canada.

When he was still in junior high, Lincoln was editor of the unofficial school paper. He spent hours every week putting it together. Many teachers and students had weekly subscriptions to it. When a copy of the newspaper ended up in the principal's hands about two months later, the principal felt that he needed to approve further editions before copies were circulated. It all went fine until the Delwin Vriend case started to surface in November $1996 .^{2}$ Lincoln, by that time, was sure of himself, and he decided to write about the case and how it is okay to be gay.

This single article resulted in the banning of the newspaper for two weeks. According to the principal, this was a paper that went

${ }^{2}$ Delwin Vriend, an educator at Kings College, Edmonton was dismissed in 1991 on the pretext that his employment violated the institution's antiqueer religious policy. When the Supreme Court of Canada decided in Vriend's favor on April 2, 1998, in his legal challenge to have sexual orientation read into the Alberta Individual Rights Protection Act, the Government of Alberta abided by the decision and extended provincial human rights legislation to prohibit discrimination against queer persons. The Supreme Court's decision aligned with Section 15(1) of the Canadian Charter of Rights and Freedoms. Sexual orientation is a category of person protected by equality provisions in this section where it is considered analogous to other personal characteristics listed there. 
home to families, so it was inappropriate to have an article like that in it. The principal felt that it would negatively influence some families and the school would get complaints. Lincoln published the article anyway, and the story about Delwin Vriend caused sales of the newspaper to double. The school received no complaints. The principal got quite upset, and he couldn't do anything about it because Lincoln distributed the newspaper off school property. Quite smart, eh?

However, the issue with the newspaper made Lincoln vulnerable to attack in some places. He didn't care, though, and nothing really serious happened to him until the following April when he was sexually assaulted. He told his best girlfriend who told her friends. Eventually, the person who abused Lincoln found out. He told the principal that Lincoln was spreading rumors about him. When Lincoln finally had the guts to explain the truth, police, psychologists, and his parents were called into the school. There were seven people in the room, including his parents who asked him if the story was true. He wasn't "out" to his parents then, so the pressure led him to tell them that he made the whole story up just to get even with that person. This was the only lie that he told during the whole thing. Lincoln was expelled from school and sent to see a psychologist because they said that he had disturbed the learning environment for students in the school.

Lincoln has told me so many more stories, and each seems just as terrible as this one. Yet Lincoln always seems to be an optimist who sees the good side of things, and he makes the best out of each situation. Like anyone, he has his moments, but he always comes back and picks himself up again. And, through it all, he still manages to care about the people who are most important in his life. If only a lot more people were like Lincoln, it would be cool. 


\section{Cartoon: "Eighteen and I Like It?"}

\section{Michael Brown}

Michael is a twenty-two-year-old gay male who has a fine arts degree. Michael's art has been featured in Edmonton's queer Times.10 Magazine and in the University of Alberta's Gateway student newspaper.
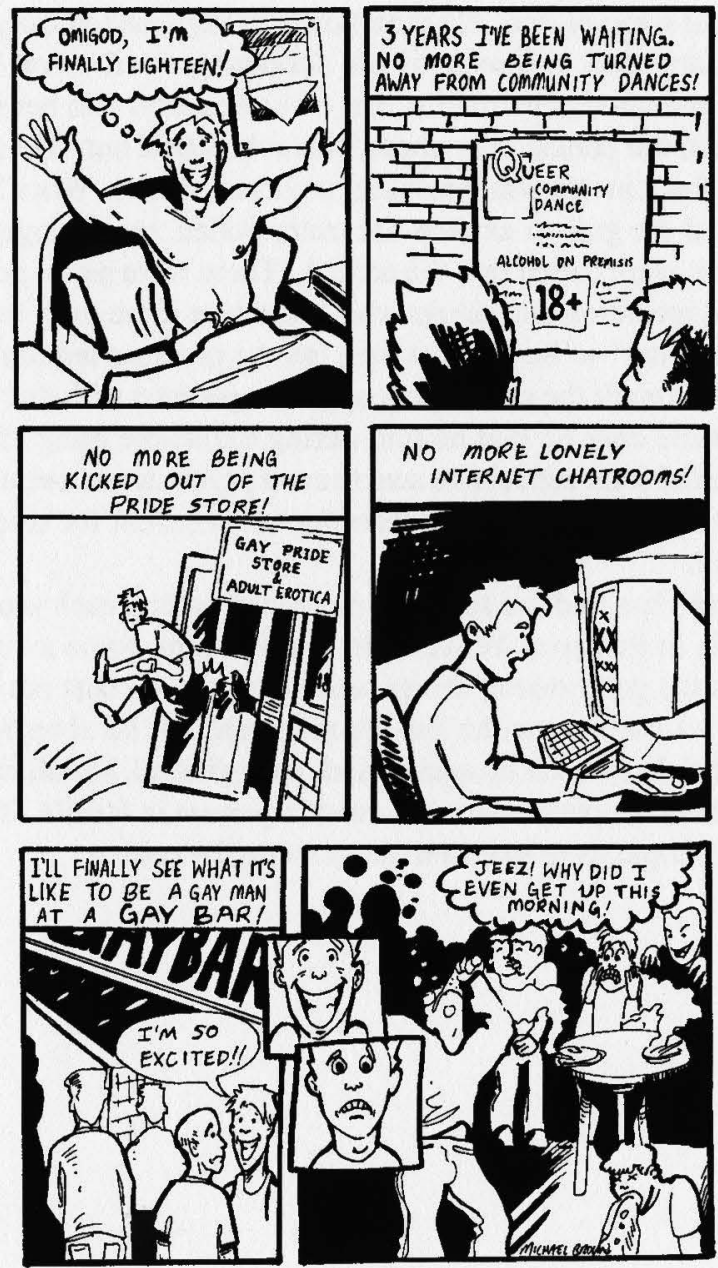


\title{
Until Never Again André P. Grace
}

\author{
Rage hard \\ Resist deeply and long \\ And long for what might be \\ For the many queer students and teachers \\ Assaulted \\ Assaulted by the fists \\ Assaulted by the words \\ Of enemies afraid \\ Of those they don't know or understand \\ Ignorance is violence \\ That leads to more violence \\ Never forget \\ Until never again \\ Never forget \\ Until never again
}

Rage hard for the queer boy with the battered face

Blood swimming in his sad eyes

There is no room for the tears that need to flow

They left his locker in shambles

And stuffed his beaten body into it

Wednesday was a very hard day at school

Never forget
Until never again

Rage hard for the queer girl

Her chest tattooed with a pocketknife

The caked blood concealing a hateful slash

Hacked by her schoolmates

D-Y-K-E

She cries alone in an alley afraid to go home

Friday night was not this girl's night out

Never forget

Until never again 
Rage hard for the queer teacher

A lump in his throat

Tears in his eyes

Because he found pictures of naked men

And a note on his car windshield

$$
\text { F-A-G-G-O-T }
$$

Someone seems to know

He walks afraid in his school

$\mathrm{He}$ finds no refuge there

Not even in the staff room

Where fag jokes are just more spit in his face

$$
\text { Rage hard }
$$

Resist deeply and long

And long for what might be

For the many queer students and teachers

Assaulted

Assaulted by the fists

Assaulted by the words

Of enemies afraid

Of those they don't know or understand

Ignorance is violence

That leads to more violence

Never forget

Until never again

\section{Works Cited}

Alberta's Education Partners. A Vision and Agenda for Public Education. Edmonton: Authors, 2000.

Alberta Teachers' Association. Teaching in Alberta: A Teacher Education Learning Resource. Edmonton: Authors, 2001.

Ashley, Christopher, dir. Jeffrey. Metro-Goldwyn-Mayer Studios, 1995.

Berlanti, Greg, dir. The Broken Hearts Club. Meanwhile Films, 2000.

Bird, Antonia, dir. Priest. Miramax, 1994. 
Bull, Chris. "Ahead of the Class: Anthony Colin and his Peers Take On a School District for their Right to be Out." The Advocate 11 Apr. 2000: 24-33.

Epstein, Debbie and Richard Johnson. Schooling Sexualities. Briston, PA: Open University Press, 1998.

Equality for Gays and Lesbians Everywhere (EGALE). "Canada Watch: Who's Doing What." 1998. <http://www.egale.ca/ features/watch.htm>

Fitzgerald, Thom, dir. The Hanging Garden. Metro-Goldwyn-Mayer Studios, 1997.

Friend, Richard A. "Choices, not Closets: Heterosexism and Homophobia in Schools." Beyond Silenced Voices: Class, Race and Gender in the United States. Eds. Lois Weis and Michelle Fine. New York: State University of New York Press, 1993.

Giroux, Henry A. Fugitive Cultures: Race, Violence and Youth. New York: Routledge, 1996.

National Education Association, American Psychological Association and Partners. Just the Facts about Sexual Orientation and Youth: A Primer for Principals, Educators and School Personnel. Washington: Authors, 1999.

Ritter, John. "Gay Students Stake their Ground." USA Today on the

Web 17 Jan. 2000. <http://www.usatoday.com/news/ acovtue.htmt>

Ryan, Caitlin and Donna Futterman. Lesbian and Gay Youth: Care and Counseling. New York: Columbia University Press, 1998.

Surrey Teachers' Association (STA). "Moving Beyond Silence": Addressing Homophobia in Elementary Schools. Surrey, BC: Author, 2000.

Youth Understanding Youth (YUY). YUY's Philosophy and Mission Statement. Edmonton: Author, 1998. 